\title{
Valuasi Pemanfaatan Sumberdaya Perikanan Ekosistem Terumbu Karang Pada Taman Nasional Kepulauan Seribu, Jakarta
}

\author{
Julianto Subekti, Suradi Wijaya Saputra, Imam Triarso
}

\author{
Program Studi Manajemen Sumberdaya Perairan \\ Jurusan Perikanan Fakultas Perikanan dan Ilmu Kelautan Universitas Diponegoro \\ Jl. Prof. Soedharto, SH Semarang
}

\begin{abstract}
Abstrak
Ekosistem terumbu karang merupakan salah satu ekosistem di laut yang mempunyai banyak manfaat. Kegiatan utama pemanfaatan dalam kawasan TNKpS yang mendominasi adalah kegiatan perikanan. Penelitian ini dilaksanakan pada bulan Agustus sampai dengan bulan Oktober 2011 di yang berada dalam kawasan SPTN 1 - SPTN 3 Taman Nasional Kepulauan Seribu, Jakarta. Penelitan ini bertujuan untuk mengetahui jenis dan tingkat pemanfaatan sumberdaya ekosistem terumbu karang di kawasan TNKpS dan nilai ekonomi total manfaat ekonomi terumbu karang di TNKpS. Metode penelitian yang digunakan adalah metode survei sedangkan untuk pengambilan contoh yang digunakan adalah metode purposive sampling. Jumlah responden yang diambil dalam penelitian ini adalah 71 orang, yaitu 33 orang nelayan, 12 orang pembudidaya, 4 orang penangkapan ikan hias, 15 orang masyarakat sekitar kawasan dan 10 orang pihak Taman Nasional Kepulauan Seribu. Nilai ekonomi total (Total Economic Value) manfaat ekosistem terumbu karang di TNKpS seluas 98.176 ha adalah sebesar Rp. 20.241.981.976 per tahun dengan rincian manfaat langsung Rp. 12.718.678.584 (69,24\%), manfaat tidak langsung Rp. 2.319.596.989 (11,46\%), dan manfaat pilihan Rp. 1.451.321.082 (7,17\%)
\end{abstract}

Kata Kunci: Valuasi ekonomi, Terumbu karang, Nilai Ekonomi Total

\begin{abstract}
Coral reef ecosystem is one of the marine ecosystem that has many benefits. The main activities on the use of coral reef ecosystems are dominated fisheries activities. This study was conducted on August to October 2011 in the region within SPTN 1 - SPTN 3 of the park. The study aims to know the type and use of coral reef ecosystem in the park and total economic value of coral reef ecosystem in the park. The research methods used is a descriptive survey method and sampling method used is a purposive sampling method. The number of respondents in this study were 71 people, that is 33 fishermen, 12 farmers, 4 people catching ornamental fishes, 15 of the 10 officers of the park. The total economic value of coral reef ecosystem in 98.176 ha of the park is amount Rp. 20.241.981.976 per year compose of direct use benefits Rp. 12.718.678.584 (69,24\%), indirect use benefits Rp. 2.319.596.989 (11,46\%), and optional use benefit Rp. 1.451.321.082 (7,17\%).
\end{abstract}

Keywords : Economic Valuation, Coral Reef, Total Economic Value 


\section{Pendahuluan}

Sebagai negara kepulauan terbesar di dunia, Indonesia dikelilingi oleh konfigurasi pulaupulau yang berjumlah lebih dari 17 ribu pulau, dengan wilayah laut seluas 5,8 juta km2 (termasuk ZEEI) atau sekitar 75\% dari total wilayah Indonesia, dan memiliki panjang garis pantai $95.181 \mathrm{~km}$ (Bengen dan Retraubun, 2006). Kepulauan Seribu merupakan gugusan kepulauan yang terletak di sebelah Utara Jakarta, tepat berhadapan dengan Teluk Jakarta. Kepulauan Seribu terdiri dari pulaupulau karang sebanyak 105 buah dengan total luas wilayah daratan sebesar $8,7 \mathrm{~km}^{2}$. Luas wilayah 107.489 hektar dengan sekitar 44 buah pulau termasuk ke dalam taman nasional. Kegiatan utama pemanfaatan di sekitar ekosistem terumbu karang yang berada dalam kawasan taman nasional meliputi kegiatan perikanan dan wisata bahari. Hampir sebagian besar masyarakat yang berada di kawasan Taman Nasional Kepulauan Seribu berprofesi sebagai nelayan. Hal ini mengindikasikan tingginya tingkat ketergantungan masyarakat terhadap sumberdaya perikanan. Mengingat pentingnya fungsi ekologi dan ekonomi dari ekosistem terumbu karang, maka perlu dilakukan pendugaan nilai ekonomi ekosistem terumbu karang dalam kawasan Taman Nasional Kepulauan Seribu yang dapat digunakan untuk merencanakan pengelolaan ekosistem terumbu karang yang lebih berkelanjutan.

\section{Materi dan Metode}

Materi penelitian ini meliputi nilai fungsi dan manfaat ekonomi ekosistem terumbu karang yang diperoleh dari informasi masyarakat maupun data dari pihak pemegang kebijakan yang berada dalam kawasan Taman Nasional Kepulauan Seribu. Metode penelitian yang digunakan adalah metode survei. Metode penelitian survei adalah suatu metode penelitian yang dilakukan dengan tujuan utama untuk membuat gambaran atau deskripsi tentang suatu keadaan secara obyektif. Metode ini digunakan untuk memecahkan atau menjawab permasalahan yang sedang dihadapi pada situasi sekarang. Data primer diperoleh dengan pengisian kuisioner, melakukan wawancara serta observasi langsung di lapangan. Data sekunder merupakan data dan informasi yang bersumber dari instansi - instansi terkait. Teknik pengambilan sampel adalah purposive sampling, dimana pengambilan sampel dilakukan dengan pertimbangan tertentu (Nasoetion, 2007).

Menurut Fauzi (1999), lahirnya konsep valuasi ekonomi didasarkan pada masalah yang sering timbul dalam pengukuran surplus konsumen untuk barang dan jasa non konvensional, sehingga menggunakan konsep Total Economic Value :

$$
\mathrm{TEV}=\mathrm{TUV}+\mathrm{NUV}
$$

Dimana :

TEV : Total Economic Value
TUV : Total Use Value
NUV : Non Use Value

Menurut Fauzi (1999), nilai pakai ini secara lebih rinci diklasifikasikan lagi menjadi : $\mathrm{TUV}=\mathrm{TDUV}+\mathrm{TIUV}+\mathrm{OV}$

Dimana :

$\begin{array}{ll}\text { TUV } & : \text { Total Use Value } \\ \text { TDUV } & : \text { Total Direct Use Value } \\ \text { TIUV } & : \text { Total Indirect Use Value } \\ \text { OV } & : \text { Option Value }\end{array}$

\section{Hasil dan Pembahasan}

\section{Gambaran Umum Lokasi Penelitian}

Secara fisik, batas-batas wilayah Kepulauan Seribu antara lain, sebelah Utara berbatasan dengan Laut Jawa atau Selat Sunda. Sebelah Timur berbatasan dengan Laut Jawa. Sebelah Selatan berbatasan dengan daratan utama Pulau Jawa dengan Kecamatan Cengkareng, Penjaringan, Pademangan, Tanjung Priok, Koja, Cilincing dan Tangerang. Sebelah Barat berbatasan langsung dengan Laut Jawa atau Selat Sunda (TNKpS, 2005). Luas Taman Nasional Kepulauan Seribu (TNKpS) tersebut hanya $15 \%$ dari luas Kabupaten Kepulauan Seribu, akan tetapi sangat berperan 
dalam pembangunan Kepulauan Seribu. Potensi yang ada di daerah TNKpS sangat besar, dari $66 \%$ keseluruhan potensi budidaya kelautan dan $73 \%$ dari keseluruhan potensi wisata bahari yang ada di Kepulauan Seribu.

Tabel 1. Luas Kawasan Taman Nasional Kepulauan Seribu berdasarkan bentuk lahan

\begin{tabular}{clrr}
\hline No. & \multicolumn{1}{c}{ Bentuk Lahan } & Luas (Ha) & Persentase (\%) \\
\hline 1 & Daratan Pulau & 576.91 & $0,43 \%$ \\
2 & Rataan Pasir & 4.350 .379 & $4,05 \%$ \\
3 & Karang & 98.176 & $0,09 \%$ \\
4 & Perairan Laut & 102.463 .535 & $95,32 \%$ \\
\hline & Jumlah Total & 106.912 .090 & $100 \%$ \\
\hline
\end{tabular}

Sumber : Laporan Statistik TNKpS (2009)

Tabel 2. Pembagian Wilayah Kerja Seksi Pengelolaan Taman Nasional Wilayah Lingkup Balai Taman Nasional Kepulauan Seribu

\begin{tabular}{clrr}
\hline No. & \multicolumn{1}{c}{ SPTN Wilayah } & Luas (Ha) & Persentase (\%) \\
\hline 1 & SPTN Wilayah I Pulau Kelapa & 39.932 & $37,15 \%$ \\
2 & SPTN Wilayah II Pulau Harapan & 45.128 & $41,98 \%$ \\
3 & SPTN Wilayah III Pramuka & 22.429 & $20,87 \%$ \\
\hline & Jumlah Total & 107.489 & $100 \%$ \\
\hline
\end{tabular}

Sumber : Laporan Statistik TNKpS (2009)

\section{Kondisi Ekosistem Terumbu Karang}

Jenis-jenis terumbu karang yang dapat ditemukan dalam kawasan Taman Nasional Kepulauan Seribu antara lain, jenis karang keras (hard coral) seperti karang batu (massive coral) misalnya Monstastrea dan Lobophyllia, karang meja (table coral), karang kipas (Gorgonian), karang daun (leaf coral), karang jamur (mushroom coral) dan jenis karang lunak (soft coral) (TNKpS, 2005).

Berdasarkan penelitian yang dilakukan Balai Taman Nasional Kepulauan Seribu yang bekerja sama dengan Lembaga Swadaya Masyarakat (LSM) TERANGI didapatkan hasil penutupan terumbu karang dari tahun 2003 sampai dengan 2009 di beberapa lokasi, adalah sebagai berikut:

Tabel 3. Persentase penutupan karang keras (KK), karang mati (KM) dan indeks mortalitas (IM) dengan perbandingan antar lokasi dan antar waktu $(2003,2005,2007,2009)$

\begin{tabular}{ccccc}
\hline Lokasi & Tahun & Karang Keras & Karang Mati & Indeks Mortalitas \\
\hline Pulau Pramuka & 2003 & 34,7 & 34,2 & 0,5 \\
& 2005 & 16,0 & 10,9 & 0,4 \\
& 2007 & 34,6 & 53,4 & 0,6 \\
& 2009 & - & 2,4 & 0,2 \\
\hline Pulau Panggang & 2003 & - & - & - \\
& 2005 & 42,8 & 33,3 & 0,4 \\
& 2007 & 32,5 & 21 & 0,4 \\
& 2009 & - & 9,1 & 0,2 \\
\hline Pulau Harapan & 2003 & 42,7 & 36,0 & 5,0 \\
& 2005 & 26,4 & - & - \\
& 2007 & 48,6 & 26,1 & 0,4 \\
& 2009 & - & 6,4 & 0,2 \\
\hline
\end{tabular}




\section{Kondisi Sosial Ekonomi}

Hampir sebagian besar penduduk yang berada di kawasan ini beragama Islam dan penduduk yang tinggal di pulau-pulau tersebut merupakan pendatang yang berasal dari suku Betawi, Banten, Bugis dan Madura. Mayoritas rumah yang dibangun di kawasan ini adalah permanen dan semi permanen dan rata-rata setiap rumah mempunyai fasilitas MCK. Aliran listrik di kawasan ini bergantung pada PLTD yang masing - masing tiap Kelurahan berjumlah 2 buah, sehingga listrik di kawasan ini tidak menyala sepanjang hari. Listrik mulai menyala dari pukul 5 sore hingga 7 pagi. Mata pencaharian di wilayah TNKpS, berdasarkan kondisi wilayahnya yang terletak di pulau-pulau kecil dan dikelilingi laut ini, mayoritas berpencaharian sebagai nelayan. Berdasarkan data Himpunan Nelayan Seluruh Indonesia (HNSI) Kepulauan Seribu, terdapat 1721 orang nelayan di seluruh Kepulauan Seribu.

\section{Nilai Ekonomi Ekosistem Terumbu Karang TNKpS Manfaat Langsung}

Pada nilai manfaat langsung didapatkan dari beberapa sektor, antara lain perikanan tangkap, perikanan budidaya, dan penangkapan ikan hias. Pada sektor perikanan tangkap didapatkan hasil sebesar Rp. 2.235.205.385. Hasil ini diperoleh dari beberapa alat tangkap seperti bubu sebesar Rp. 2.045.784.042, muroami sebesar Rp. 415.193.333, jaring sebesar Rp. 3.179.169.167, dan pancing sebesar Rp. 3.300.675.000. Pada sektor perikanan budidaya didapatkan hasil sebesar Rp. 3.492.330.000. Hasil ini diperoleh dari beberapa sektor budidaya rumput laut sebesar Rp. 1.782.950.000 dan transplantasi terumbu karang sebesar Rp. 1.709.280.000. Pada sektor penangkapan ikan hias didapatkan hasil sebesar Rp. 1.540.518.000

\section{Manfaat Tidak Langsung}

Pada nilai manfaat tidak langsung didapatkan dari nilai yang dapat diidentifikasi dari keberadaan ekosistem terumbu karang di TNKpS berupa peran penting dari ekosistem tersebut sebagai physical protection global life sebesar US\$ 276.5 per ha (Hansen et al, 2003) yang diacu oleh Fauzi dan Anna (2005), maka nilai manfaat tidak langsung dalam kawasan ekosistem terumbu karang di kawasan TNKpS adalah Rp. 2.319.596.989

\section{Manfaat Pilihan}

Pada nilai manfaat pilihan ekosistem terumbu karang TNKpS dalam penelitian ini didekati dengan nilai keanekaragaman hayati terumbu karang, dimana nilai dari manfaat pilihan ini sebesar US\$ 17.3 per ha (Hansen et al, 2003 dalam Fauzi dan Anna, 2005), maka nilai manfaat pilihan dalam kawasan ekosistem terumbu karang di kawasan TNKpS adalah Rp. 1.451.321.082

Tabel 4. Nilai Ekonomi Total Ekosistem Terumbu Karang TNKpS

\begin{tabular}{|c|c|c|c|}
\hline & Jenis Manfaat & Nilai (Rp./ Tahun) & \multirow[t]{2}{*}{ Kontribusi } \\
\hline & \multirow{2}{*}{$\begin{array}{l}\text { Manfaat Langsung: } \\
\text { a. Perikanan Tangkap }\end{array}$} & & \\
\hline \multirow{8}{*}{1.} & & & \\
\hline & - $\quad$ Bubu & Rp. 2.045.784.042 & $10,11 \%$ \\
\hline & - Muroami & 415.193 .333 & $2,05 \%$ \\
\hline & - Jaring & Rp. 3.179 .169 .167 & $16,31 \%$ \\
\hline & - Pancing & Rp. 2.045 .784 .042 & $15,71 \%$ \\
\hline & b. Perikanan Budidaya & & \\
\hline & - $\quad$ Rumput Laut & Rp. 1.782 .950 .000 & $8,81 \%$ \\
\hline & - $\quad$ Transplantasi Karang & Rp. 1.709 .280 .000 & $8,64 \%$ \\
\hline & c. Pengkapan Ikan Hias & Rp. 1.540 .518 .000 & $7,61 \%$ \\
\hline 2. & Manfaat Tidak Langsung & Rp. $\quad 2.319 .596 .989$ & $11,46 \%$ \\
\hline \multirow[t]{2}{*}{3.} & Manfaat Pilihan & Rp. 1.451 .321 .082 & $7,17 \%$ \\
\hline & Nilai Ekonomi Total & Rp. 20.241.981.976 & $100 \%$ \\
\hline
\end{tabular}

Sumber : Data Primer, diolah (2012) 


\section{Kesimpulan dan Saran}

Berdasarkan hasil penelitian yang telah dilakukan maka dapat diambil kesimpulan sebagai berikut:

1. Nilai ekonomi total (Total Economic Value) manfaat ekosistem terumbu karang TNKpS seluas 98.167 ha adalah sebesar Rp. 20.241.981.976 per tahun. Sumbangan nilai terbesar berasal dari manfaat langsung yaitu sebesar Rp. 16.471.063.905 per tahun $(81,37 \%)$ disusul oleh manfaat tidak langsung sebesar Rp. 2.319.596.989 (10,3\%), dan yang terakhir adalah manfaat pilihan sebesar Rp. 1.451.321.082 (7,17\%).

2. Nilai ekonomi terbesar dari manfaat langsung, berasal dari kegiatan perikanan tangkap, yaitu sebesar Rp. 8.940.821.542 (44,17\%), diikuti oleh kegiatan perikanan budidaya sebesar Rp $5.241 .594 .364(25,89 \%)$

Saran yang dapat diberikan dalam penelitian ini adalah :

1. Perlu adanya penelitian lanjutan mengenai valuasi ekonomi yang berkelanjutan terhadap kondisi ekosistem terumbu karang yang berada dalam kawasan TNKpS.

2. Perlu adanya perhatian pemerintah terkait dalam hal pengelolaan ekosistem terumbu karang yang berada dalam kawasan TNKpS.

\section{Ucapan Terimakasih}

Pada kesempatan ini penulis mengucapkan terima kasih kepada Bapak Dr. Ir. Suradi Wijaya Saputra, MS selaku dosen pembimbing utama dan Bapak Ir. Imam Triarso, M.Si, selaku dosen pembimbing anggota yang telah memberikan saran, perhatian dan bimbingan kepada penulis dalam pelaksanaan penelitian dan penulisan skripsi ini; Bapak Sairan selaku pembimbing lapangan yang telah membimbing selama melakukan penelitian di Balai Taman Nasional Kepulauan Seribu; dan kedua orangtua yang selalu memberikan doa, semangat dan kasih sayang tiada henti.

\section{Daftar Pustaka}

Adrianto, Luky. 2005. Modul Pengenalan Konsep dan Metodologi Valuasi Ekonomi Sumberdaya Pesisir dan Laut. Pusat Kajian Sumberdaya Pesisir dan Lautan. Institut Pertanian Bogor. Bogor.

Bengen, D dan A. Retraubun . 2006. Menguak Realitas Dan Urgensi Pengelolaan Berbasis Eko-Sosial Sistem Pengelolaan Pulau-Pulau Kecil. Bogor : Pusat Pembelajaran dan Pengembangan Pesisir dan Laut (P4L).

TNKpS. 2005. Laporan Akhir Monitoring dan Pemetaan Kerusakan Ekosistem Terumbu Karang Kepulauan Seribu. P.T. Sewun Indo Konsultan. Jakarta.

Fauzi, A. 1999. Ekonomi Sumber Daya Alam dan Lingkungan. PT Gramedia Pustaka Utama. Jakarta.

Fauzi, A., dan Anna, S. 2005. Pedoman Valuasi Ekonomi Kawasan Konservasi Laut (KKL). Departemen Kelautan dan Perikanan, Direktorat Konservasi, Ditjen Pesisir dan PulauPulau Kecil.

Nasoetion S. 2007. Metode Research (Penelitian Ilmiah). Jakarta : Bumi Aksara.

TERANGI. 2009. Laporan Jangka Panjang Terumbu Karang 2003 - 2007. 112hal. 